\title{
Home-Based Physical Exercise Program for Cardiac Rehabilitation in the Context of COVID-19
}

\author{
Cristiano Penas Seara Pitanga1, Carmem Cristina Beck², and Francisco José Gondim Pitanga ${ }^{3, *}$ \\ ${ }^{1}$ Universidade Católica de Salvador (UCSAL), Salvador, BA, Brazil \\ ${ }^{2}$ Instituto Federal da Santa Catarina (IFSC), Palhoça, SC, Brazil \\ ${ }^{3}$ Universidade Federal da Bahia (UFBA), Salvador, BA, Brazil
}

*Corresponding author: Francisco José Gondim Pitanga, Faculdade de Educação-Universidade Federal da Bahia (UFBA), Salvador, BA, Brazil, E-mail: pitanga@lognet.com.br

Received: 09 Sep, 2020 | Accepted: 22 Sep, 2020 | Published: 26 Sep, 2020

Citation: Pitanga CPS, Beck CC, Pitanga FJG (2020) Home-Based Physical Exercise Program for Cardiac Rehabilitation in the Context of COVID-19. J Hear Health 6(1): dx.doi.org/10.16966/2379-769X.156

Copyright: (C) 2020 Pitanga CPS, et al. This is an open-access article distributed under the terms of the Creative Commons Attribution License, which permits unrestricted use, distribution, and reproduction in any medium, provided the original author and source are credited.

\section{Introduction}

Despite the publication in several manuscripts of information on the importance of continuing physical activity and reducing sedentary behavior [1], the importance of physical activity being considered essential during decrees of social isolation or quarantine [2], the pandemic of the new coronavirus has been causing a significant reduction in physical activity in the world population [3].

Data from Fitbit, a physical activity management application, shows a significant decrease in the number of steps taken by users of the tool worldwide. The severity of the decline in the number of steps varied from country to country, with European countries showing the most dramatic change, ranging from $7 \%$ to $38 \%$ in step count during the week ending March 22, 2020. Specifically in Brazil, in the same period, the reduction was approximately $15 \%$ in the number of daily steps of people [3] (Table 1).

This scenario has been worrying researchers in the cardiovascular area, considering that the reduction in the practice of physical activity during and after the pandemic, mainly by patients with cardiovascular diseases, can lead to the worsening of the clinical condition of patients with arterial hypertension, acute myocardial infarction and heart failure among other cardiovascular health problems. A recent point of view argues that physical inactivity can promote atrophy and cardiac dysfunction, luminal narrowing of peripheral vessels, arterial stiffening and impaired endothelial function [4].

In addition, the fact that we do not know when the vaccine will be discovered, leads us to believe that the pandemic is likely to last for some time. In this sense, considering that people with cardiovascular diseases are part of the risk group for the new coronavirus, physical activity performed at home, remotely, can be an excellent strategy for the continuity of physical exercises in this particular population.
It is important to note that even before the pandemic, several authors have already advocated cardiac rehabilitation done remotely, or telerehabilitation. Programs addressing various components of rehabilitation, including physical activity, have been proposed by different organizations $[5,6]$. In the context of the new coronavirus pandemic, entities such as the American Association for Preventive Cardiology, advocate telerehabilitation as an excellent strategy for patients with cardiovascular diseases who cannot travel to cardiac rehabilitation centers, both because of mobility difficulties and because of proposals for physical isolation resulting from the COVID-19 pandemic [7].

A recent publication suggests that remote cardiac rehabilitation programs should be implemented during the pandemic, since the risks of physical inactivity outweigh the risks of well-planned programs [8]. Thus, this point of view aims to propose a physical exercise program done at home and guided by an online physical education professional, for people with cardiovascular diseases.

\section{Home-Based Physical Exercise Program Guided by an Online Physical Education Professional}

The innCARDIO exercise program: Exercise Cardiology consists of 4 phases: 1) pre-participation assessment in physical exercise programs; 2) obtaining morphological measures (assessment of body fat distribution);3) training prescription, with individualized physical exercise guidance at the appropriate levels for each participant [9] and; 4) monitoring/supervision of training through weekly teleconsultations.

Phase 1 includes the assessment of the individual's health profile and stratification of cardiovascular risk [10]. At this stage, those classified as medium/high risk are initially referred for consultation with a cardiologist to perform complementary exams and evaluate the 
Table 1: Decline in step counts during the week ending March 22, 2020 (Fitbit, 2020).

\begin{tabular}{|l|c|}
\hline \multicolumn{1}{|c|}{ COUNTRIES } & $\%$ \\
\hline North America & \\
\hline Canada & $14 \%$ \\
\hline United States & $12 \%$ \\
\hline Central America & \\
\hline Mexico & $13 \%$ \\
\hline South America & \\
\hline Peru & $18 \%$ \\
\hline Brazil & $15 \%$ \\
\hline Argentina & $24 \%$ \\
\hline Europe & \\
\hline Portugal & $38 \%$ \\
\hline United Kingdom & $9 \%$ \\
\hline France & $11 \%$ \\
\hline Africa & \\
\hline South Africa & $7 \%$ \\
\hline Asia & \\
\hline Russia & $17 \%$ \\
\hline India & $6 \%$ \\
\hline China & \\
\hline
\end{tabular}

risk/benefit of exercising in the individual's current clinical condition. Still in this phase, pre-participation assessment can also be used with the application of anamnesis, PAR-Q questionnaire and analysis of cardiovascular risk [9] in order to better understand the health profile of the postulant for practice of physical exercise.

Phase 2 refers to the self-assessment, supervised by the Physical Education Professional, of the distribution of body fat through the Conicity Index (CI). The CI is an anthropometric indicator for assessing the distribution of body fat that, for its determination, uses the measurements of body weight, height and waist circumference. The CI value is calculated using the following mathematical equation [11]:

\section{$\mathrm{CI}=$ waist circumference $/ 0.109 \times$ square root of weight/height}

The cutoff points for identifying the distribution of fat in the abdomen region, as well as its superiority in relation to other anthropometric indicators for identifying excess abdominal fat, were determined in Brazil $[12,13]$. In the Brazilian population, the cutoff points stipulated were: 1.25 for men, 1.18 for women up to 50 years old and 1.22 for women over 50 years old [12].

Phase 3 corresponds to the prescription of individualized physical exercise at the appropriate levels for each patient, aiming at increasing functional capacity, improving and controlling hemodynamic variables (chronotropic and inotropic) and increasing health levels in the secondary prevention of cardiovascular diseases [14]. The prescription will be based on the type, duration, intensity and weekly frequency of physical exercises [9], including aerobic training (cardiorespiratory) and resistance training (neuromuscular), which will be directed to their performance at home, or outdoors, in places close to the residence following the biosafety protocols determined by the health authorities. Aerobic training can be developed through circuit-based activities at home, lasting 20 to 30 minutes, or walking lasting 40 to 60 minutes a day, while muscle endurance training can be developed through muscle strength/endurance activities for lower and upper limbs, in addition to strengthening the abdomen and trunk. The sessions will be proposed to be developed between 3-5 days a week. The intensity of the training will be controlled using the Borg scale, in addition to the perception of increased respiratory rate, sweating, and heart rate. Each complete exercise session will consist of: warmup, through stretching exercises; aerobic training; muscle resistance training and calm down, through relaxation activities.

Phase 4 corresponds to supervision and follow-up with weekly teleconsultations carried out by Physical Education Professionals in order to promote the necessary adjustments to the program and lead the progression of each patient. In addition to monitoring adaptations to physical exercises, changes in body fat distribution and physiological responses are also evaluated by the Physical Education Professional, as well as monitoring health levels and cardiological variables with regular consultations with a cardiologist.

It should be noted that in all phases of the program the Physical Education professional will use technological resources, such as: applications, teleconsultations and online training spreadsheets. In addition, program participants will be counseled regarding the importance of reducing sedentary behavior for health, that is, the time they spend sitting, lying down or reclining, with the exception of hours of sleep $[1,15]$.

\section{Final Considerations}

Therefore, it is of fundamental importance for patients with cardiovascular diseases, the maintenance and/or beginning of the practice of physical activity done at home or outdoors, and with the guidance of a Physical Education Professional online, during the pandemic of the new coronavirus. A physical exercise program with medical supervision and guidance from a Physical Education Professional will be of great importance for the current moment we are experiencing. In addition, considering that the pandemic may last for some time, as well as that cardiac patients are at risk for the worsening of the clinical condition resulting from Covid-19, this practice may become routine for these specific people. It is also noteworthy the various benefits caused by the practice of physical activity in the prevention and treatment of different cardiovascular diseases, as yet another argument for continuing physical exercise sessions, even when performed at home or outdoors.

\section{References}

1. Pitanga FJG, Beck CC, Pitanga CPS (2020) Physical Activity and Reduced Sedentary Behavior during Coronavirus Pandemic. Arq Bras Cardiol 114: 1058-1060.

2. Pitanga FJG, Beck CC, Pitanga CPS (2020) Should physical activity be considered essential activity during the COVID-19 pandemic? Int J Cardiovasc Sci 33: 401-403.

3. Fitbit (2020) The Impact of Coronavirus on Global Activity.

4. Peçanha T, Goessler KF, Roschel H, Gualano B (2020) Social isolation during the COVID-19 pandemic can increase physical inactivity and the global burden of cardiovascular disease. Am J Physiol Heart Circ Physiol 318: H1441-H1446.

5. Harold JG, Bass TA, Bashore TM, Brindis RG, Brush JE Jr, et al. (2013) ACCF/AHA/SCAI 2013 update of the clinical competence statement on coronary artery interventional procedures: a report of the American College of Cardiology Foundation/American 
Heart Association/American College of Physicians Task Force on Clinical Competence and Training (writing committee to revise the 2007 clinical competence statement on cardiac interventional procedures). Circulation 128: 436-472.

6. Batalik L, Filakova K, Batalikova K, Dosbaba F (2020) Remotely monitored telerehabilitation for cardiac patients: A review of the current situation. World J Clin Cases 8: 1818-1831.

7. Scherrenberg $M$, Wilhelm $M$, Hansen $D$, Völler $H$, Cornelissen $V$, et al. (2020) The future is now: a call for action for cardiac telerehabilitation in the COVID-19 pandemic from the secondary prevention and rehabilitation section of the European Association of Preventive Cardiology. Eur J Prev Cardiol 1-21.

8. Teixeira CRR (2020) Coronavirus Disease (COVID-19) Pandemic: An Opportunity Window to Implement Home-Based Cardiac Rehabilitation. Int J Cardiovasc Sci 33: 282-283.

9. Pitanga FJG (2019) Orientações para Avaliação e Prescrição de Exercícios Físicos Direcionados à Saúd. CREF4/SP.

10. American College of Sports Medicine, Thompson WR, Gordon NF, Pescatello LS (2010) In: Pescatello LS, Gordon NF, Pescatello LS (eds) ACSM's guidelines for exercise testing and prescription. $8^{\text {th }}$ edition, Philadelphia: Lippincott Williams \& Wilkins.
11. Valdez R (1991) A simple model-based index of abdominal fat. J Clin Epidemiol 44: 955-956.

12. Pitanga FJG, Lessa I (2005) Anthropometric indicators of obesity as a screening tool for high coronary risk in adults in the city of SalvadorBahia. Arq Bras Cardiol 85: 26-31.

13. Eickemberg $M$, Amorim LDAF, Almeida MCC, Pitanga FJG, Aquino EML, et al. (2020) Abdominal obesity in ELSA-Brasil (Brazil's Longitudinal Study of Adult Health): construction of a latent gold standard and evaluation of the accuracy of diagnostic indicators. Cien Saude Colet 25: 2985-2998.

14. Nelson ME, Rejeski WJ, Blair SN, Duncan PW, Judge JO, et al. (2007) Physical activity and public health in older adults: recommendation from the American College of Sports Medicine and the American Heart Association. Med Sci Sports Exerc 39: 1435-1445.

15. Pitanga FJG, Matos SMA, Almeida MDCC, Patrão AL, Molina MDCB, et al. (2019) Association between leisure-time physical activity and sedentary behavior with cardiometabolic health in the ELSA-Brasil participants. SAGE Open Med 7: 1-9. 